\title{
Mineração
}

\section{A abordagem da economia ambiental no contexto da mineração}

\author{
Raul Oliveira Neto \\ Eng.Minas, Doutorando \\ Laboratório de Processamento Mineral-Programa de Pós-Graduação \\ em Engenharia de Minas, Metalúrgica e dos Materiais - PPGEMM / UFRGS \\ E-mail:raul@ct.ufrgs.br \\ Carlos Otávio Petter \\ Eng.Minas, Doutor \\ Laboratório de Processamento Mineral-Programa de Pós-Graduação \\ em Engenharia de Minas, Metalúrgica e dos Materiais - PPGEMM / UFRGS \\ E-mail:cpetter@vortex.ufrgs.br
}

\section{Resumo}

Muito se fala da necessidade de preservação do meio ambiente e nas obrigações legais em que os empreendimentos devem se enquadrar, porém pouco se definem os custos que tudo isso determina. Esse artigo tenta mostrar que é possível se estabelecerem instrumentos econômicos juntamente com os jurídicos. Estes trariam um equilíbrio maior ao sistema, já que se baseiam na idéia de que a oneração do empreendedor (princípio poluidorpagador) pode chegar a um limite admissível, além do qual a comunidade representada pelo poder público poderia arcar através de uma negociação. Seria, em síntese, a introdução do conceito do princípio beneficiário-pagador em parte dessa negociação. Surge a importância da contabilidade dos custos ambientais desde a fase do projeto até a operação e finalização. São colocadas as bases teóricas desses conceitos da Economia Ambiental, indicados os níveis que poderiam ser estabelecidos e algumas sugestões para operacionalizar um novo sistema dentro de bases legais econômicas.

Palavras-chave: meio ambiente, mineração, economia, custos, poluição, impactos.

\begin{abstract}
Much has been written about the need to preserve the environment and the legal duties enterprises are subject to, but little has been established in terms of the environmental cost all this implies. This article attempts to show that it is possible to define economic and juridical instruments together that could bring a better balance to the system. These aspects are based on the idea that entrepreneurs' cost (polluting-payer principle) may reach an acceptable limit, beyond which the community, represented by the public power, could take on costs through negotiation. In short, that would be an introduction of the beneficiary-payer principle concept as part of this deal. Environmental costs accountancy would be then highly regarded, from project phase to operation and closure. The theoretical bases of this Environmental Economy Approach are introduced, as well as the levels that could be established and some suggestions to operate a new system upon legal-economic bases.
\end{abstract}

Keywords: environmental, mining, economy, costs, pollution, impacts, rehabilitation. 


\section{Introdução}

A análise de um projeto não deve ser restrita ao aspecto dos impactos ambientais, pois corre-se o risco de gerar um outro impacto negativo, que é o da não implantação do empreendimento, barrando-se o desenvolvimento e o progresso. Por isto, a questão se tornará muito mais compreensível se associada à ciência econômica.

A economia ambiental seria uma maneira de controlar a ação das atividades degradadoras, com a aplicação de instrumentos econômicos. Estes estabeleceriam soluções econômicas para o gerenciamento ambiental em conjunto com os instrumentos jurídicos (Lanna, 1996).

Em IBRAM (1992), introduz-se o assunto da seguinte forma : O descarte de resíduos no ar, águas e solos vai gradativamente tornando o meio ambiente escasso, no sentido de ser incapaz de absorver quantidades crescentes de resíduos. Com base nesse cenário, os recursos ambientais adquirem uma escassez progressiva e um valor cada vez maior, transformando-se em bens econômicos propriamentes ditos". Considera-se o meio ambiente como um conjunto de bens e serviços que são consumidos pela atividade e, portanto, podem ser tratados como recursos escassos e sua utilização terá como meta o maior benefício à sociedade.

Na mineração, além desses descartes, há à degradação do meio físico devido a explotação dos minérios. Gera-se, portanto, uma segunda escassez, considerando que as jazidas minerais são como bens não renováveis.

\section{Tipos de abordagem econômica}

As soluções econômicas procuram estabelecer, por meio da imposição de preços, taxas, subsídios, rateios e outros instrumentos econômicos, o mesmo equilíbrio buscado pela aplicação dos instrumentos legais (Lanna, 1996). Seguindo esse raciocínio, existem dois ti- pos de abordagem econômica, a tradicional e a alternativa. Na primeira, faz-se a análise custo-benefício e, na segunda, a análise custo-efetividade.

\subsection{Princípio poluidor- pagador}

Para a abordagem econômica tradicional (análise custo-benefício), o importante seria repassar todo o custo pela poluição ambiental, aplicando, então, o princípio poluidor-pagador. Surgem, então, duas alternativas, ou o empreendedor paga à sociedade pela poluição gerada, ou assume todo o custo em implantar as medidas de controle ambiental.

\subsection{Princípio beneficiário- pagador}

Para a abordagem econômica alternativa (análise custo-efetividade), surge a necessidade da definição de um segundo princípio, o princípio beneficiário-pagador. Neste, o estabelecimento de metas ou objetivos estratégicos através de negociação social é um imperativo, já que nem sempre é possível a valoração do custo social ou dos custos externos decorrentes da atividade. Nesse caso, são concedidos subsídios aos empreendedores para que adotem alternativas mais eficientes, sob os pontos de vista econômico ou ambiental, sendo que tais benefícios oneram a comunidade afetada.

\section{Aplicabilidade à mineração}

O setor mineral está na base da pirâmide produtiva, sendo produtor de bens, gerador de empregos diretos e indiretos. Além disto, gera divisas aos países e uma boa parcela de arrecadação de impostos a estados e municípios. Portanto, dentro da abordagem econômica, o princípio beneficiário-pagador seria $\mathrm{o}$ mais adequado ao setor, porém o princípio poluidor-pagador deve também ser considerado para o abatimento parcial dos custos de poluição. O ideal, portanto, seria um equilíbrio entre os dois princípios.
Na problemática ambiental da indústria de mineração, a política econômica-ambiental pode auxiliar na definição de critérios ou regulamentos, que não se baseiem apenas como fixação de níveis de quantidade e qualidade (Poulin \& Sinding, 1994).

Os economistas baseiam-se na teoria de que deva existir algum nível ótimo de externalidades, na qual a soma total dos benefícios menos os custos é maximixada, ou seja, os benefícios totais líquidos são maximizados. Deverá existir um ponto onde o nível da atividade econômica é aceitável para ambas as partes, onde o benefício privado líquido marginal é igual ao custo externo marginal, e que corresponda a uma certa quantidade de poluição ou de geração de impactos envolvendo efeitos negativos ao meio ambiente externo.

Essa situação pode melhor ser entendida se analisada através do gráfico esquemático geral apresentado na Figura 1 (Allister, L., Beil S. \& Cox A., 1994).

\section{Importância e análise dos custos internos}

A idéia que rege a economia ambiental deve estar alicerçada em base sólida e na aplicação prática dos mecanismos ou instrumentos de gestão ambiental descritos. É importante que a noção de custos ambientais esteja presente de uma forma clara, ou seja, tendo-se a real idéia de valores e grandezas monetárias, e sua relação na estrutura de custos que envolvem o processo de mineração.

Esses custos podem ser classificados em dois tipos:

1) Custos internos, ou custos privados, relacionados à empresa mineradora.

2) Custos externos, ou custos sociais, gerados pelas externalidades, ou a influência dos impactos da atividade minerária à comunidade direta e indiretamente envolvida.

A análise dos custos internos é importante, porque são estes que a em- 
presa titular da licença mineral terá que assumir na implantação das medidas prescritas. É a base para o desenvolvimento sustentável, sendo que, para haver a atividade econômica minerária gerando benefícios sociais e econômicos, deve haver rentabilidade para a empresa mineradora. Isso significa a internalização dos custos de abatimento da poluição, sendo fator primordial na abordagem econômica ambiental. Atualmente, o sistema legal de controle está funcionando dentro dessa filosofia, ou seja, a empresa geradora da poluição absorve todos os custos inerentes, abrangendo a mitigação, compensação e recuperação. Importante também salientar que esses custos têm natureza cumulativa, ou seja, quanto mais tarde são implantadas as medidas, maior será o dispêndio da empresa, conforme é mostrado na Figura 2, onde uma situação de alto nível de impacto pode gerar custos significativos de remediação.

O comparativo da Tabela 1 mostra, para cada tipo de mineração abordado nessa análise de custos, como ficam os custos anuais e mensais para as medidas ambientais. A relação custo ambiental / operacional é apresentada, assim como a taxa custo ambiental/t de minério produzido, para cada caso.

O peso das medidas ambientais ( $\%$ custo ambiental / custo operacional) para as diferentes empresas é mostrado na análise da Tabela 1 (última coluna). Observa-se uma disparidade nesses percen-

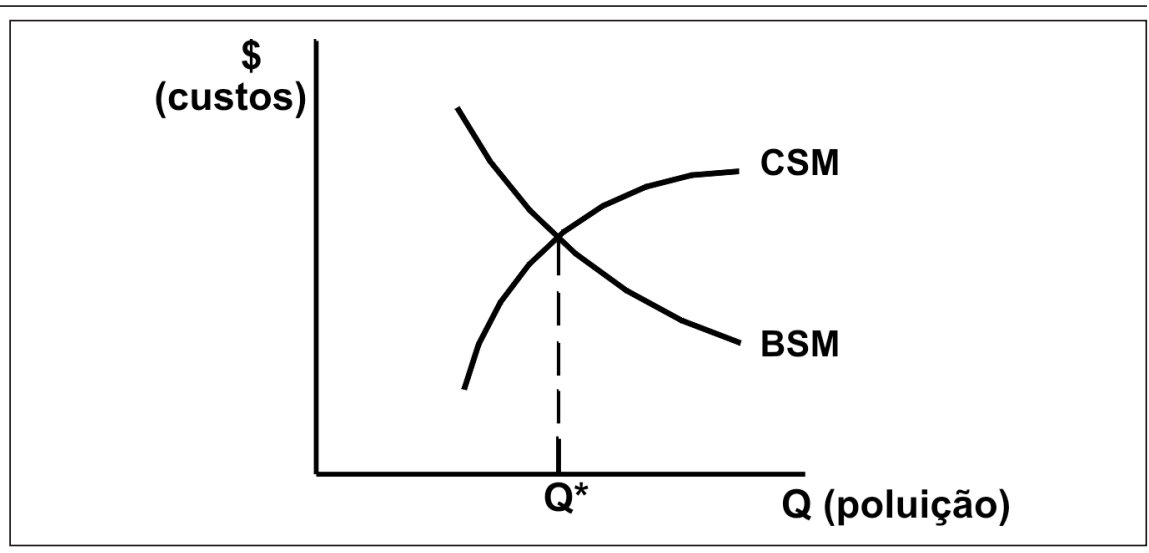

Figura 1 - Abordagem econômica-ambiental, gráfico demonstrativo. (BSM: benefício social marginal; CSM: custo social marginal; Q: nível de poluição (degradação sem medidas); Q*: nível ótimo de reabilitação).

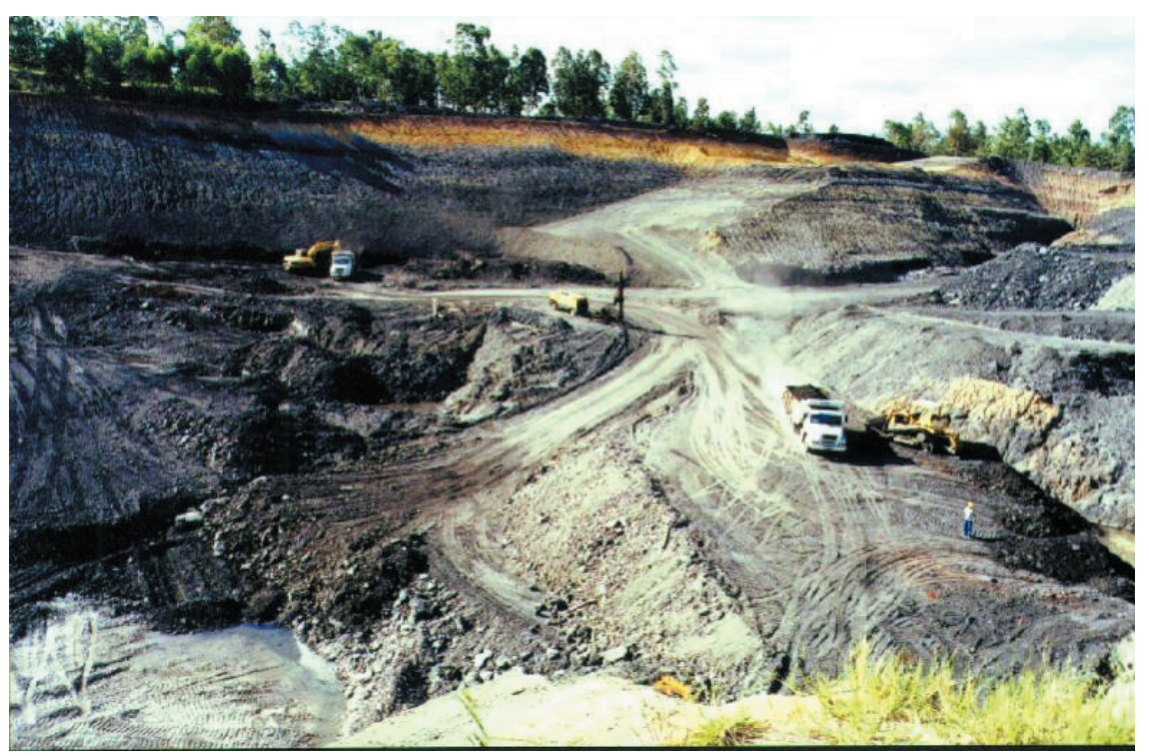

Figura 2 - Vista geral de cava de mina de carvão (mineração de grande porte).

Tabela 1 - Comparação operacional x custo ambiental por porte de empresa de mineração. Fonte: Modificado de Neto, 1999.

\begin{tabular}{c|c|c|c|c|c|c}
\hline $\begin{array}{c}\text { Tipo de } \\
\text { mineração } \\
\text { (porte) }\end{array}$ & $\begin{array}{c}\text { Custo } \\
\text { operacional } \\
\text { mensal médio } \\
\text { (US\$) }\end{array}$ & $\begin{array}{c}\text { Custo } \\
\text { ambiental } \\
\text { mensal } \\
\text { médio (US\$) }\end{array}$ & $\begin{array}{c}\text { Produção } \\
\text { mensal } \\
\text { média (t) }\end{array}$ & $\begin{array}{c}\text { Custo } \\
\text { operacional } \\
\text { (US\$/t) }\end{array}$ & $\begin{array}{c}\text { Custo } \\
\text { ambiental } \\
\text { (US\$/t) }\end{array}$ & $\begin{array}{c}\text { \% Custo ambiental } \\
\text { /custo operacional }\end{array}$ \\
\hline $\begin{array}{c}\text { AREIA } \\
\text { pequeno porte }\end{array}$ & $2,270.00$ & 800.00 & 2.000 & 1.14 & 0.40 & 35,1 \\
\hline $\begin{array}{c}\text { PEDREIRA } \\
\text { médio porte }\end{array}$ & $23,300.00$ & $2,700.00$ & 8.800 & 2.65 & 0.31 & 11,7 \\
\hline $\begin{array}{c}\text { CARVÃO } \\
\text { grande porte }\end{array}$ & $663,600.00$ & $30,500.00$ & 300.000 & 2.21 & 0.10 & 4,5 \\
\hline
\end{tabular}


tuais, onde pequenas empresas (areia) estão com $35,1 \%$, médias empresas estão com $11,7 \%$ e grandes empresas (carvão) estão com 4,5\%. A explicação para isso está no fato de que o custo ambien-

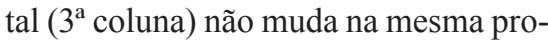
porção que a produção. (Figura 3)

Essa conclusão pode ser antagônica à premissa de que, quanto "mais se produz, mais se polui" e, por conseqüência, o custo com o controle ambiental teria que variar na mesma proporção.

A questão é que isso, na realidade nem sempre ocorre, devido à semelhança nos sistemas de controle, que independem muitas vezes do tipo ou do porte da mineração. A coluna Custo Ambiental $\left(3^{\mathrm{a}}\right)$ inclui os custos de licenciamento ambiental, onde incluem-se as taxas do órgão licenciador e os estudos ambientais, que não estão sendo proporcionais à produção. As diferenças estão nas medidas de controle ambiental que dependem da área superficial envolvida, por exemplo, numa grande mineração (carvão), haverá necessidade de um investimento maior na implantação de sistema de valetas de drenagem com contenção de sólidos, do que para uma mineração de porte médio (pedreira), cuja área superficial impactada é muito menor (Figura 4). Portanto há realmente uma sobrecarga nos custos das empresas de pequeno e médio porte, o que parece não ocorrer para as de porte maior, evidenciando-se a necessidade de se criar mecanismos de negociação social com repasse de parte desse custo excedente para a comunidade, representada pelo poder público.

Recentemente, em um projeto de uma mina de Caolim para um jazimento localizado na África Ocidental, onde fezse uma previsão detalhada dos custos previstos e incluem-se os custos ambientais, conforme é mostrado na Tabela 2 , a seguir, concluiu-se que o custo ambiental por tonelada de produção prevista ficaria em 0,14 US\$ / t. Se compararmos com o custo médio/t ponderado com a tonelagem, entre os três tipos de minerações apresentados na Tabela 1 (média dos valores da $6^{\mathrm{a}}$ coluna ), que fica em 0,11 US\$/t, constataremos que esses valores são muito próximos, ficando a diferença por conta dos percentuais de segurança embutidos pelos índices de projeto. Mas, de qualquer forma, confirmam que os levantamentos feitos refletem a realidade atual do setor.

\section{Conclusões}

A partir da análise das colocações feitas, podem ser traçadas as seguintes conclusões principais, que servirão para orientar empreendedores e órgãos de controle, no sentido do estabelecimento de critérios de negociação entre o poluidor e a comunidade afetada, que não só envolvam instrumentos legais mas também os instrumentos econômicos:

Tabela 2 - Resumo da participação no custo anual, para um projeto de mineração Caulin. Fonte: Modificado de Neto, 2001.

\begin{tabular}{c|c|c}
\hline Atividade & $\begin{array}{c}\text { Custo Anual } \\
\text { (US\$) }\end{array}$ & $\begin{array}{c}\text { Custo / Tonelada } \\
\text { (US\$) }\end{array}$ \\
\hline Mina à céu aberto & $96,300.00$ & 2.40 \\
\hline Mina subterrânea & $8,000.00$ & 0.20 \\
\hline Usina de tratamento & $138,680.00$ & 3.50 \\
\hline Medidas de controle ambiental & $76,800.00$ & 0.14 \\
\hline
\end{tabular}

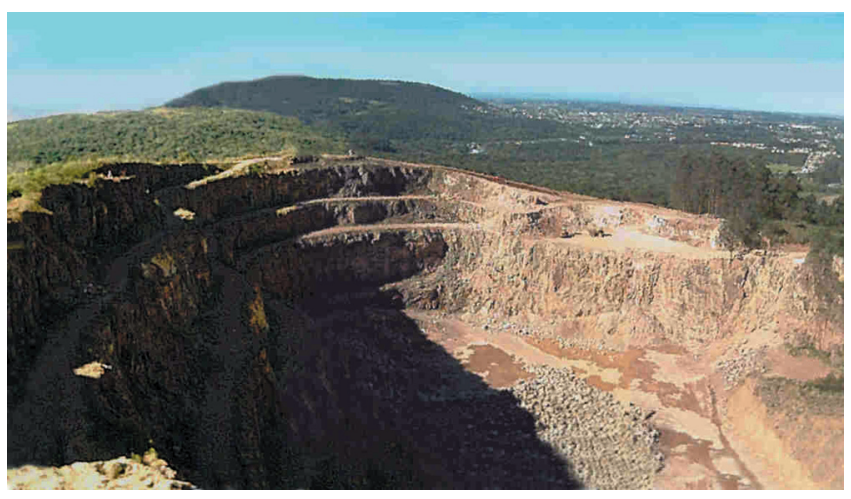

Figura 3 - Vista geral de cava de pedreira (mineração de médio porte), observa-se que o nível de impacto é menor que o da mina de carvão, porém existe o mesmo nível de exigência de recuperação; alternativas de utilização futura do local devem entrar em negociação envolvendo a participação do poder público e a comunidade.

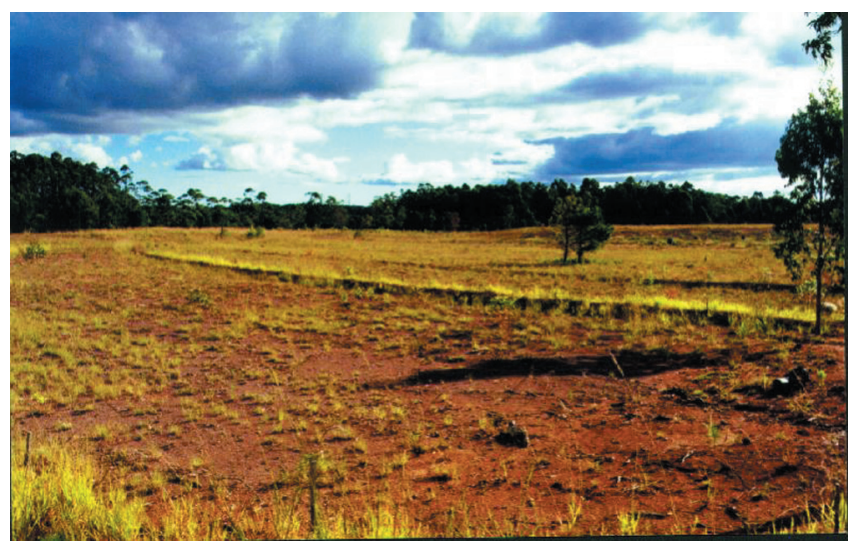

Figura 4 - Vista geral de área já recuperada da cava de mina de carvão (mineração de grande porte). Pode-se ter a idéia do nível de exigência quanto à qualidade final do trabalho de recuperação da área, o que reflete em benefícios à comunidade diretamente afetada. 
1. A empresa deve contabilizar seus custos de controle ambiental e divulgá-los à comunidade e órgãos de controle, o que serviria como base para uma negociação social com vistas ao estabelecimento do princípio benefiário-pagador, desonerando o poluidor (empresa) a partir de um determinado nível de custo que seria assumido pela comunidade ou pelo poder público.

2. O poder público, através dos órgãos de controle, poderia também conceder subsídios como forma de incentivar o empreendedor, e estaria, então, dessa forma, assumindo parte do custo ambiental e estabelecendo o princípio beneficiário-pagador.

3. É sabido, a partir dos levantamentos em empresas e dos estudos ambientais, e como demonstrado na Tabela 1 , que o peso dos custo das medidas ambientais sobre o custo operacional mínimo das empresas de mineração tem oscilado em torno dos $4 \%$, portanto deveria se estabelecer um limite de 5\% para a relação "custo ambiental / custo operacional”, aci- ma do qual o princípio beneficiáriopagador passaria a ser estabelecido, como forma de onerar a comunidade através de mecanismos econômicos a serem definidos pelo poder público, aqui representados pelos órgãos de controle e prefeituras.

4. A previsão de custos ambientais feita já na fase de projeto para novos empreendimentos é importante e pode também servir como instrumento na negociação dos níveis de oneração futuros para empreendedor e comunidade.

\section{Referências Bibliográficas}

ALLISTER, L., BEIL S., COX A. An economic and public policy perspective on mine site reclamation. In: Proceedings of the Third International Conference on Environmental Issues and Waste Management in Energy and Mineral Production. Perth, Western Australia: 1994, p. 21-24.

IBRAM-Instituto Brasileiro de Mineração. Mineração e meio ambiente. BrasíliaBrasil: 1992. p. 1-126.
LANNA, H. Introdução à microeconomia e à valoração social de projetos. Porto Alegre: UFRGS, Instituto de Pesquisas Hidráulicas, 1996. p. 1-27.

LANNA, H. Instrumentos econômicos de gerenciamento ambiental. Porto Alegre: UFRGS, Instituto de Pesquisas Hidráulicas, 1996. p. 1-19.

NETO, R.O. Avaliação do sistema de licenciamento ambiental vigente para a mineração. Uma nova proposta de metodologia e procedimentos. Porto Alegre: UFRGS/Programa de PósGraduação em Engenharia de Minas, Metalúrgica e Materiais, 1999. p. 31-35. (Dissertação de Mestrado).

NETO, R.O. Projeto de explotação do jazimento de caulim de Ketou respeitando o meio-ambiente, Bénin, Africa Ocidental. França: Centro de Estudos Superiores para a Segurança e o Meio Ambiente MineirosAlés: 2001, p. 173.

POULIN, R., SINDING, K. Mining economics and the environment. In: PROCEEDINGS OF THIRD INTERNATIONAL CONFERENCE ON ENVIRONMENTAL ISSUES AN WASTE MANAGEMENT IN ENERGY AND MINERAL PRODUCTION. Perth, Western, Australia: 1994. p. 1-32.

Artigo recebido em 02/06/2003 e aprovado em 23/11/2004.

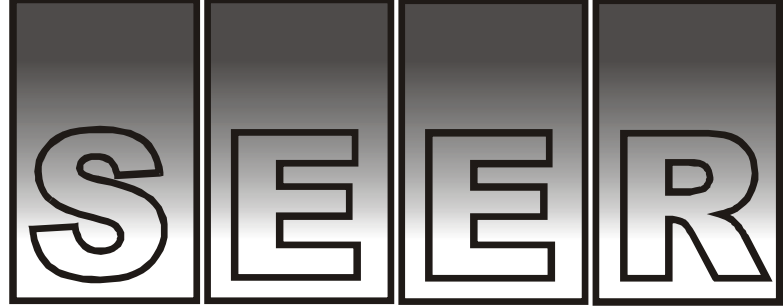

SISTEMA ELETRÔNICO DE EDITORAÇÃO DE REVISTAS
A questão SEER ou não SEER deixou de existir:

\section{Agora os autores utilizarão o SEER \\ para enviar e acompanhar seu artigo até o momento da publicação. REM 69 anos divulgando Ciência}

